\title{
Repositioning the victim in victimology through theory: The concentric model
}

\author{
Ochuko Oluku \\ The Department of Criminology and Security Studies \\ Western Delta Universty, Oghara \\ Phone: 07035687927 \\ Email: ochukooluku2@gmail.com
}

\begin{abstract}
This work examines the inadequacies of the current victimological and criminological theories for not giving the rightful focus to the victim as their subject matter. The two predominant strands of current theorizing, 'native' and adapted perspectives were questioned for blaming the victim for his victimization or attributing his predicament to socio - structural variables, instead of the crime perpetrator. The legal status of the victim is not considered by both perspectives: hence, the paper proposes a concentric model, which seeks to restore the victim to his rightful place within the criminal justice system. The victim is appropriately portrayed as an inactive player in crime causation, who is at the receiving end of the activities of outlaws. New concepts, 'former normal', 'victim status' and 'victimal' state are introduced to properly capture the 'alterative' harm offenders inflict on their victims, some of which many never recover from. It attempts a reconstruction of the process of victimization, and with the aid of two empirical case studies, demonstrates the possibility of discovering the pattern of offender victimization through mass studies of crime victimization data. Results from the studies can be used to formulate strategies to halt crime and break the cycle of victimization. The model holds great promise for research and policy on prevention of victimization and victim support and treatment in the criminal, or any alternative justice system.
\end{abstract}

\section{Introduction}

Victimology as field of study by itself or within mainstream criminology has since its founding in the 1940's made reasonable progress in the areas of measurement, the response of the criminal justice system to victims and in victim trauma and services (Zaykowski\&Campagna, 2014), but not so much in the area of theory building and development. The core theories in the current literature emanated from, and reflect the thoughts of the founding fathers, Hans von Hentig and Benjamin Mendelsohn. These theories address the subject matter of victimology midstream by pointing at the role of the victim in the etiology of victimization. By so doing, what should have been the main theme, the 'victim' and 'victimization' as a phenomenon is lost in the search for causes which are of doubtful value.

The neglect of informative focus on the position and plight of the victim is a fundamental flaw in current victimological theorizing with misleading consequences on victims in criminal justice practices in Nigeria and around the world. Though the victim is widely regarded as integral part of the subject matter of criminology, it is not recognized (Yusuf \&Yahaya, 2014). This is troubling because the victim perspective was for a long time missing in criminology before its rediscovery or reemergence in the 1950s (Adler, et al, 2007; Ferguson \&Turvey, 2009). Central to this error is the prevailing trend of creating victim culpability by adducing victimization to individual choices, location and other 'exposure' factors, visibly leaving out the offender as though his harmful behavior is a socially approved check on or reprimand of the victim.

This paper sets out to correct this anomaly by trying to meet the following objectives: 
i. Examining the nature of victimization as an object of study

ii. Attempting a reconstruction of its processes, with a view to providing some insights to the possibility for remediation to future victimization

iii. Setting out the implication of our analytical model for research and policy. After exploring the gaps left by current theory, it advances a fresh thesis that illuminates the personhood of the victim as a brutalized shadow of a former self. The paper relies strongly on the current position of the law on the place of the victim, other relevant literature, and two illustrative case studies for the practical relevance of the model.

\section{The present state of theory}

There are two streams of victimological theories that are trending in the literature. The first is native to the field and are elaboration of the thinking of the pioneers. The others are adaptation of the theories form related fields. Zaykowski and Campagna (2014) did an analysis of the representation of theories in some recent victimology textbooks and came out with the following categories which we shall adopt for use here:
i. victim precipitation
ii. exposure and opportunity
iii. learning and culture
iv. control/ critical
v. others.

The first two belong to the first order of theories with the exposure/ opportunity bracketing life-style theory, deviant place theory, routine activity theory and structural choice theory. The remaining two are borrowed adaptations.

Victim precipitation theory posits that crime victims attract victimization to themselves by their provocative and instigatory behaviour during interactions between perpetrators and their victims. This postulation was made by Hans von Hentig in a 1941 article in which he advanced the view that, both offender and victim are to blame for any incident of victimization. His views are shared by Benjamin Mendelsohn, another criminologist of the period. Mendelsohn was the first to publish a classification of crime victims. Of his six categories of victims, four carry different degrees of blame for their victimization, one was truly innocent while the last was made of pretenders to being victims of one crime or the other. The rest of the first order theories follow the same pattern of victim blaming. Lifestyle theory developed by Hindelang, Gottfredson and Gurofalo attributes the risk of victimization to the type of people one relates with and the lifestyle one leads. To illustrate, a person who suffers frequent rape or robbery attacks may be attracting the attacks to $\mathrm{him} /$ herself because there are rapists and robbers among his circle of associates. Routine activity and structural choice theories further touch on routine and structurally related activities and placements within social contexts which provide exposures for criminal victimization. On its part the deviant place theory, takes a different approach by taking the blame off the individual victim but locates it in the criminal places he visits. For them victimization can be stopped if people avoid certain places. Victimization boils down to the choices the individual makes or fail to make.

Social learning theories look at the social contexts where norms, values, meanings and expectation are shared during interaction between offenders and victims. During the process participants accept violence and aggressive behaviour as normal part of social life. At the same time others learn to accept their victimization. Victimization and being victimized becomes a sub-cultural norm in deviant settings where the values are

Journal of Management and Social Science Research, Volume 1, Numbers 1/2, 2020 
shared and transmitted within the group. The claim of normative consensus between victimizers and victims on their respective statuses and corresponding fortunes/ misfortunes to the extent that the values are mutually accepted and transmitted is preposterous and contestable.

Social control theory, another of the borrowed perspectives attributes victimization and offending to low selfcontrol resulting from weakness of the control system within the group settings. Under this condition some persons are prone to lean toward criminal behaviour. Victims of crimes in environment of weak social control and low self - control are persons who adopt life styles that are risky.

The foregoing is a brief summary of the existing theories. It is not the intention of this undertaking to do a comprehensive critique of them except to point out the shortcomings that provide the gap for our present work. Of vital significant here is their failure to explain who and what a victim is within the physical and socio-legal contexts that made him. If they had I am sure they would not embark on the misadventure of shielding law breakers, and to batter their battered victims. They neither make mention of the outlawed actions nor ill motives of the criminal offender, not to talk of the devastations they wreak on society and the sufferers of their harm. Rather the victim is held in contemptuous anonymity and callously subjected to a ridiculous blame game. $\mathrm{He}$ is portrayed as a person who invites victimization to himself. $\mathrm{He}$ is either negotiating his victimization by his choices and behaviour in the course of active interaction with the offender or some internal and external factors are working together to enhance his victimization. The pre-meditative role of the perpetrator, his motivations, treacheries and dastardly acts against the innocent victim is ignored in the hope of hood winking us to believe that he is merely responding to the invitation of his victims to steal, kill and destroy. Where this is not so, the victimizer - victimized interface is portrayed to be an orchestration and enhancement of social control failures and other structural influences. Both positions are in effect shielding and exonerating the criminal offender while at the same time intellectually revictimizing the victim. This is dangerous for the position of the law, individual rights and liberties and the need to hold people accountable for criminal breaches. The negative effect of this on the criminal justice system is that the victim is subjected to serial revictimization and not many give a thought to what can be done to him and his circumstances (Yusuf and Yahaya, 2014). There is therefore a need for a shift from the present direction of theorizing to address the personhood, plight and right of crime victims with the compassion it deserves and to transfer the blame to where it belongs.

\section{Legal origin of the victim}

Victimology needs to be stood on its feet. To do so requires locating its subject matter, the victim, in its legal origins. The victim is the creation of the breach of the contractual obligation between citizen and citizen on the one hand and citizens and the state, on the other. It is this social contract which necessitated the enactment of law to prohibit unwanted behaviours and to moderate and regulate relations. Local and international criminal law prohibits all acts considered harmful to the state and its citizens whether they are carried out by an individual, a group, an organization or the government. The acts and their perpetrators are assumed to be abhorred by the rest of the compliant society and are subjected to specific sanctions.

This particular study presents a fresh thesis on the victim and the process of his victimization. It aims broadly to reposition the victim as a missing thematic focus in victimological studies. It also draws empathetic attention to victims 
through direct theoretical encounter with his personhood and condition. New concepts of 'formal normal', 'victim status' and 'victimal state' are introduced to make clearer the description of the phenomenon of victimization and its processes.

\section{Methodology}

The paper is a novel thesis or to put it more succinctly, a theoretical proposition on the nature and processes of victimization. It is based on the legal premise that a victim is an innocent sufferer of harm or loss at the hand of a criminal offender. It benefits from existing authorities on the subject. A hypothetical process of victimization is presented. Its relevance and efficacy are illustrated with two case studies, one of which incorporates data obtained in a field research in support of this work. The offender is assumed to be in agreement with the position of the law just like all other members of the society. He is aware whenever he breaks the law that he is carrying out wrongful acts against the interests of the state and other citizens. The law is a safeguard against dangerous and harmful behaviour. The connection between the eventual offender and his target victim is that of a violator of criminal legal norm and a sufferer from the acts of his violations. Hence the basic ingredients that defines a crime also establishes the victim of the crime. Among the several are the presence of a 'conduct', the existence of willful intent and an outcome (Robin, 1984; Adler et al, 2007; Dambazau, 2007). The following are the essential ingredients of 'victimhood':

i. a person or group of persons at the receiving end of a criminal conduct (or threats of it) (actusrea),

ii. the criminal conduct is carried out intentionally (mensrea) against him/them

iii. the act results in observable or verifiable harm from the act.
While the acts of the criminal offender attract correction through the criminal justice system, the state in which the victim is thrown requires addition of a fourth element: restoration, restitution or rehabilitation.

The challenge of criminology and victimology of the future is to redirect attention to the position of the victim as a non - choice predicament that is imposed discriminately and indiscriminately on people by the violent intrusion of another or others into their lives. Comprehensive understanding of the victim and victim victimization can then pave way for researches into victim treatment to give direction to appropriate treatment strategies/ efforts, and to aid victim support services. This would go a long way to rescue crime victims from their disadvantaged position in the current criminal justice system where he is a mere observer or at best a passive participant with no legal protection, and no compensation for his injury or loss (Dam Bazau, A.B. 2007).

\section{From former normal to victim status: understanding and recognizing the victimal state}

For lack of operational concepts to capture the condition of a crime victim, we adopt for use the term 'victimal state'. This is the disorganized, destabilized and traumatized condition people are put during or after criminal attacks. This condition may vary from very mild, through extreme condition of distress to total loss, disorientation or death. People may also be impacted differently in offender victimizations. So, there is variation in degree from individual to individual and in expression from one type of crime to another.

Everyone in a modern state is guaranteed a personal space of rights and freedoms that is considered inalienable within its legal norms. These rights derive from articles 330 of the United Nations Declaration on Human Rights (1948) and the provisions of other U.N. Covenants and conventions

Journal of Management and Social Science Research, Volume 1, Numbers 1/2, 2020 
safeguarding the rights and dignity of the human person. When that space is interrupted and violated by the criminal offender, there is an alteration that translates the life or fortunes of the target to that of a victim status from its 'former normal'. That alteration occurs as a result of the harm done to the private or public life of the victim, be it his physical body, his property or interests. A balanced criminal justice system should not limit itself to addressing the harmful acts of offenders, to inflict punishment on culprits. It should also address the damages or alterative changes their actions cause to victims, for purposes of restorative redress. A balanced criminal justice demands victim restoration and a good Victim Support/Rehabilitation System can be supported from both state and offenders' resources.

The victimal state or condition is both physical and mental and could involve total death, physical injuries, emotional issues and loss of material things. Victimization goes with a whole lot of debilitating garbage such as shame, grief, loss, sense of confusion, sleeplessness, anger, fear and physical pain. A multidisciplinary approach is needful to fully understand types of victimal states resulting from offender victimizations and their impact on those afflicted by them. Victim suffering is not limited to those harmed directly. The impact and extent of suffering spread needs to be understood in order to fully appreciate the overall impact of specific offender actions against their victims. Crime victims deserve the empathy and support of the rest of society as well as restorative rehabilitation by the state. The present tilted judicial system requires balancing to provide for a victim support/restoration service. More attention should be given to studying crime victims. Better knowledge will enable care givers to design appropriate therapies for different victims of crime.

\section{The structure of the process}

In designing a macro structural image of the process, it should be emphasized that victimization is externally induced and never self-inflicted. It is the deliberate product of the criminal actions of an offender in breach of the law. Criminal acts have devastating consequences on victims, putting them into states of shock, fear, pain, anger and other physical, emotional and spiritual conditions. Many victims never regain themselves again because of the permanent damage they suffer. No one in society wishes to be a victim. Even the thief who steals from other people is angry when his valuable is stolen. The secret car jacker is displeased when his own car is stolen, that he runs to the police to seek recovery of it. The rapist whose absurd passion is directed toward persons outside his own family is offended when someone else rapes his wife or daughter. Predatory crimes are abhorred by the whole of society. That is why the criminal justice system is put in place to curb crime, arrest offenders, try them and sentence the guilty to terms of punishment.

Crime is a social aberration, just as the social imperfections from which they emerge. There are always people who cannot control themselves and subject their desires and appetites to the demands of societal rules for meeting them. Among those with personal virtue of self-control are some who genuinely lack the means of satisfying their desire but would not want to go the whole hog to do so, but would rather prefer to steal a chance at a deviant route. Then there are people who for selfish reasons will want to go against legal norms even when they have the means and are capable of doing the right thing. The final choice in all of this is as weird as the crime itself: go after another person who has what he needs and take it without his/ her permission. In so doing the offender is prepared to harm his victim if he dares to resist.

There are different types of offender victimizer. They are bred under different socio -psychological settings

Journal of Management and Social Science Research, Volume 1, Numbers 1/2, 2020 
OchukoOluku: Repositioning the victim in victimology through theory: The concentric model from where they emerge to choose a crime path, train, arm themselves and go after

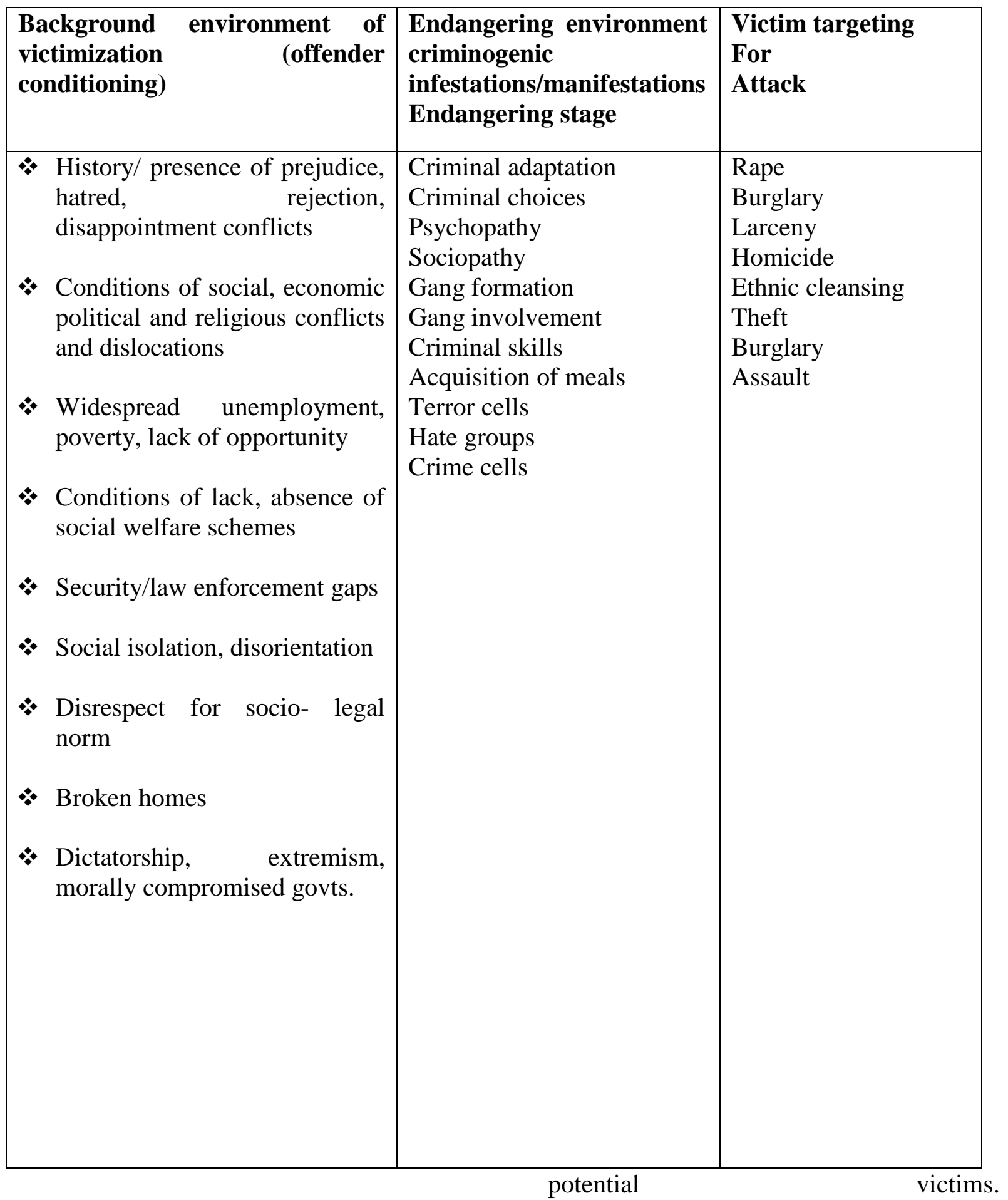

\section{Table 1: Victimization Traffic in society}

From the above chart we can see that, victimization is a one-way traffic of offender against a victim. Both the offender and the victim reside in the same socio -legal environment of any given society. The environment (the state) has both positive and negative, functional and dysfunctional elements impacting on all citizens of varied statuses and upbringings. Persons who decide on criminal conducts or careers between legal and illegal choices yield themselves willingly to negative socio-psychological pressures. The choice of crime is a private personal 
(or gang) decision that moves the potential offender into a purposive choice to satisfy self (or selves) through inflicting sufferings, losses or devastation on the collective or other members of the society who lead normal, conforming lives in the liberty of the general legal space granted everyone. While the offender does so, there are other individuals in the same society with similar or even greater challenges, and with as much handicap who chose approved options in the interest of the general good. That is why criminality cannot be excused under normal circumstances.

The victims of crime are usually ignorant of the presence or intentions of their assailants, before they are attacked. The offender in normal society is like a hunter in the forest of prey. Every prey, keeps its distance from a known hunter. There is no victim-offender negotiation of harm. No victim invites an offender to harm him/her unless in stage-managed cases (such as some reported cases of kidnappings in Nigeria in the Vanguard Newspaper of $29^{\text {th }}$ January, 2020). The offender conceals his intentions and uses disguises and tricks to put targeted victims out of their guard and to lure them within reach of assault.

It is wrong and perverse of theory to construe the personal and institutional helplessness of conquered, coerced or forcefully manipulated persons in gangs or other deviant social settings as instances of their involvement in their own victimization. The only exception could be where the victim is a criminal as well and is trapped in his/her criminal association with others. His victim status must be looked into critically before any claim to rights can be ascertained.

Victimization happens in different ways. There is instant victimization which may be caused by a sudden event or a succession of events over a short span of time. There are some where victim harm and suffering are inflicted incrementally over time resulting to progressive victimization. Yet there are others where victimization is entrenched in the social fabric of a group or society. This is institutionalized victimization. In criminal victimization (including its intellectual aspects), one thing underscores all: a party over-reaching its rights and powers to trample on another in breach of law.

\section{The concentric model}

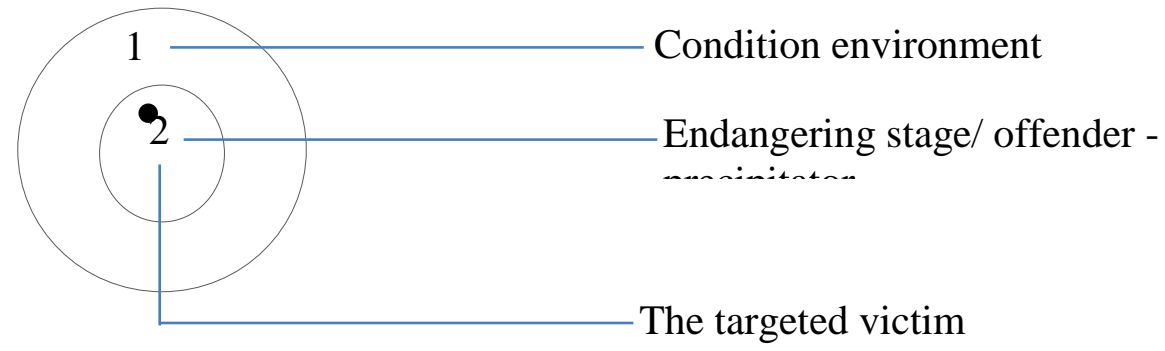

Figure 1: Victimization as invasion from the outside

Our model derives from the macroperspective discussed in the previous section. As figure 1 shows, there is an aspect of the society that creates and dangles the ease and lure of crime, in spite of its risks and absurdities. For most people it is not an option to try. Some that are tempted by its offer of easy and fast rewards are scared off by the threat of punishment. Very few dare, and it is this few who opt for the censored fruit in the behavior stock of the state that are threatening to the rest of society. The offer is not from victims as has been earlier canvased but is a criminal thought within the offender of the possibility of easy 
success through illegitimate means. Criminal success is to make another person lose for one to gain and be happy by denying them and turning their fortune into misfortune. Victimization in society is like an ill-wind or spectra of evil that builds around all or disparate units of individuals or groups. To the victim, its origin ranges from accidental, or premeditated causes to some remote abstract socio-psychological and experiential influences within the society or social group. Whatever the causes are criminal victimization is illegal and abhorrent in law governed societies. Once these negative motivations influence a criminal choice, the individual becomes a real threat factor in the community. For the criminal choice to be actualized the potential offender moves on consciously in breach of legal norms to the second phase where he plans and acts alone, or together with others in an active gang.

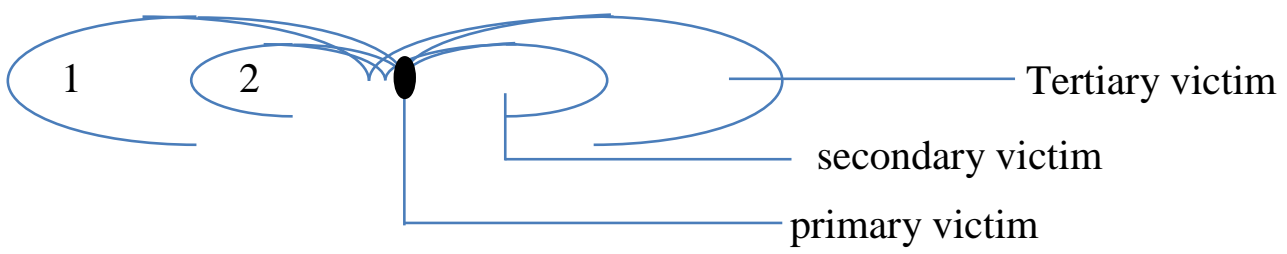

Figure 2: Victimization and its effects

The offender act against a victim does not end with him. There are extended effects beyond the primary victim. Others affected by the ripple effect on the primary victim can be tagged secondary and tertiary victims.

The victim of crime is a brutalized shadow of a former self in need of justice. Victimhood also calls for compensation and rehabilitation.

\section{Discovering victimization patterns}

It is possible to discover offender modus operandi (MOS) or the criminal methods they use to trap and harm their victims through rigorous study and analysis of mass data for individual victimization cases for crimes such as rape, homicide, pick pocketing and burglary. Mass study of data for individual crime cases would reveal the pattern of operational strategies for successful crime victimizations over time. The results of such micro - level analysis can assist law enforcement in devising intervention methods to break the cycle of offender victimizations.

Victimization is a ubiquitous phenomenon in present day societies and would need the understanding and cooperation of every one to end it. At the level of the state society, two approaches can be recommended. First is conscious and consistent effort by citizens to enthrone responsible governments for themselves that would guarantee for them programmes and policies to create a just, fair and more inclusive society where everyone has maximum care and a sense of belonging. The second is through law enforcement, to identify criminal elements and crime cells and to diffuse them. Study reports of MOs and patterns of operation of different criminal elements can serve as useful material to relevant stakeholders such as policy makers, law enforcement, ex-victims and other concerned groups in formulating anti-dotes through effective law enforcement and public enlightenment. Two case studies will throw more light on this. Before then it must be noted that this can only work if due diligence is given to proper gathering of statistics by relevant agencies. Nigerian and African governments must take this seriously if they are to develop capability in generating informed home-grown solutions to local challenges. 


\section{Case study 1}

There was once a time between the mid1980s till when electronic banking started in Nigeria that travelers to the Onitsha international market from many cities in the South-South region were being robbed on daily basis along the way. High - way robbers stopped buses, ordered passengers out and they and their drivers were stripped of all cash and valuables on them. The author resided in the commercial city of Warri at the time. Within the city of Warri itself, many traders who left their homes early for the motor park were attacked by hoodlums on the way and dispossessed of their cash. After many years of enduring this predicament, the drivers' Union and the traders in Warri (and those of some neighbouring townships like Ughelli and Sapele) met and devised a strategy to stop the recurrent victimization.

1.The major parks stopped the practice of loading passengers early. They waited till 7:00am so that the travelling merchants with their heavy luggage of cash could come to the park in the safety of day light.

2.Buses moved out of the parks in convoys of ten to fifteen vehicles, accompanied by at least three armed policemen distributed strategically in each convoy. The cost of the police escort was spread and added to the transport fare to the Onitsha market. The strategy worked. The string of trader, driver victimization was checked.

\section{Case study 2}

Our second example of a discovered and truncated pattern of offender victimization is of a non - criminal nature. It relates to the reckless riding of motor cyclists, and their wide spread traffic violations in the streets of Delta cities between 1990 and 2012. Because of high rate of unemployment during the period, a large number of youths, graduates and nongraduates turned to transportation by means of motor cycles to earn a living.

The motor cyclists popularly called Okada riders refused to provide PPEs for themselves and their passengers. Not only that, contrary to local traffic regulations they carried more than one passenger at a time, rode against traffic, over took dangerously, ignored road signs and caused hold - ups at major junctions. This resulted in scores of daily accidents on Delta roads with fatalities. The lucky survivors escaped with broken limbs. Most of these survivors ended up in bone tying centers that proliferated all over Delta at the time. After several failed attempts to bring the riders to order, the state government placed a ban on Okada in major Urban roads where these accidents were recorded. The ban took effect from September 1, 2012. From then the daily reports of motor-cycle accidents ceased.

The result of the ban was selfevident. Removal of the reckless cyclists took away the hazard from the roads. But for the sake of authenticating the positive effects of the ban, I sought statistical data for road traffic accidents from the Federal Road Safety Corps, Delta State command, covering three years before the ban and the years after. I could not get the records. As an alternative, I turned to the traditional bone fixers in the twin cities of Effurun and Warri, two of the three cities affected by the ban. They were the key players in handling the treatment of victims with serious bone fractures. Conventional hospitals were only entrusted with treatment of wounds. All 17 interviewed admitted making brisk business before the ban. Every one of them said they always had a case they were managing on hand, with some having 5 to 10 cases at a time. Significantly as at the time of the interview which spanned a two-week period between January 23, to February 6, 2020, all of them said they had not received any case

Journal of Management and Social Science Research, Volume 1, Numbers 1/2, 2020 
of fracture arising from Okada accident within the two cities since the ban.

\section{Implication for research and policy}

It is important to recognize that criminal victimization is a one directional product of unlawful offender actions. We have demonstrated the means and micro analytical possibilities in unearthing offender victimization structure and pattern. This can be researched on for each crime type through direct studies and by studying statistical data on offender victimization for different crimes in such a large scale to understand MOs and operational patterns. Such knowledge will help policy makers especially in law enforcement formulate effective remedial measures against future victimization, especially through breaking offender victimization cycles. For victimologists, studies should bring attention to the sufferings of crime victims and the sort of help they need to restore them to normalcy.

\section{Conclusion}

This paper examined the inadequacies of current victimological and criminological theories for not giving the victim and his plight the rightful focus they deserve as their subject matter. The theories in question were grouped into two: theories native to victimology (precipitation and exposure/ opportunity) and borrowed or adapted theories (cultural learning/ critical). Both positions were questioned for blaming the victim for his victimization or attributing his predicament to social - structural variables instead of the crime perpetrator. They fail to address the subject of victimhood and victimization as a legal issue deriving from lawless behaviour with devastating consequences deserving of state attention and redress.

The study corrects the error by standing on the legal premise that portrays the victim as an innocent party in a crime. The paper proposes a new paradigm, the concentric model, which sheds light on the crime victim as a subject of concern and victimization as the phenomenon of study in victimology and criminology. In this model, the victim is an inactive player in crime causation, maliciously targeted for harm and loss. It attempts a reconstruction of the process of victimization beginning with the potential offender as a disaffected member of the general society who for a variety of (illegal, unjustified) reasons deliberately takes to unlawful conduct(s), and by so doing posing real danger to other members of the society.

It attempts a reconstruction of the process of victimization, and with two empirical illustrative case studies demonstrate the possibility of discovering the pattern of offender victimization for individual crimes. This it suggests is possible through research and mass studies of victimization data for specific crimes. The results as demonstrated, can then be used to formulate remedial strategies to halt crime and break the cycle of victimization.

The model should open the way for research and policy on areas such as prevention of victimization, victimization experiences, victimal conditions and victim support/treatment generally, and in particular within the criminal justice system.

\section{References}

Adler, F. et al (2007).Criminology and the Criminal Justice System, $6^{\text {th }}$ edition", McGraw, New York.

Gerald D. R. (1984). Introduction to Criminal Justice System Principles, Procedures, Practice", Harper and Row, New York.

Dambazau, A. B. (2007). Criminology and Criminal Justice, Spectrum Books Ltd, Ibadan.

Ferguson, C. and Turvey, B. (2009).'Victimology: A brief history with an introduction to

Journal of Management and Social Science Research, Volume 1, Numbers 1/2, 2020 
OchukoOluku: Repositioning the victim in victimology through theory: The concentric model

forensic victimology', in Turvey, B. and Petherick, W. (Ed.).Forensic Victimology: Examining Violent Crime Victims in Investigative and Legal Contexts. Academic Press, USA, pp 1-32

Yusuf, Y. A. and Yahaya, S. S. (2014).

Crime Victims and Criminal
Justice in Nigeria.Global Journal of Interdisciplinary Social Sciences, 3(5):48-52. Universal Declaration of Human Rights/ United Nations https://www.un.org^universaldecla ration

Journal of Management and Social Science Research, Volume 1, Numbers 1/2, 2020 